\title{
Aetiology of Lower Respiratory Tract Infection in Benin City, Nigeria
}

\author{
${ }^{a}$ Egbagbe EE, FWACP ${ }^{b}$ mordi R.M.
}

\begin{abstract}
Patients with respiratory tract infections (RTI), Pneumonia inclusive account for a large proportion of a primary care physicians (PCP) work load and a frequent cause for prescription of antibacterial agents.

The study was aimed at analyzing the various isolated organisms obtained from sputum and to test their susceptibility and sensitivity to available antibiotics in use in the hospital and environ. Two hundred and forty eight patients seen over a one year period (January 1 , 2005 to December 31, 2005) and who were diagnosed to have lower respiratory tract infections were used for the study after an informed consent. The commonest organisms isolated were Klebsiella pneumoniae, Staphylococcus aureus and Proteus mirabilis. Most isolates groups were sensitive to ceftazidime (CAZ), Amoxycillin/clavulanate (Augmentin), cefuroxime (CXM) and ceftriaxone (CRO). The findings from this study are of relevance in the empirical treatment of lower respiratory tract infections in this environment.
\end{abstract}

\section{INTRODUCTION}

Infections of the lower respiratory tract (IRT) continue to be a major cause of morbidity in Nigeria. ${ }^{1}$ They include such conditions as pneumonia, bronchiectasis, lung abscess and acute exacerbation of chronic bronchitis (AECB) . ${ }^{2}$

Traditionally, community-acquired pneumonia has been thought to present as either of two syndromes. The typical presentation where patients present with high grade

KEY WoRDS: lower respiratory tract infections, isolates, antibiotics, susceptibility pattem

${ }^{a}$ Egbagbe EE, FWACP, Consultant Physician/Senior Lecturer ${ }^{b}$ Mordi R.m. Department of *Medicine and Medical Microbiology, University of Benin Teaching Hospital, P.m.b. 1111, Benin City, Nigeria.

All Correspondence to: Dr Egbagbe E.e. Department Of Medicine U.b.t.h., P.m.b. 1111 Benin City. fever of acute onset, cough productive of purulent sputum and pleuritic chest pain or the atypical presentation where the illness is of a more gradual onset with a low grade fever and a dry cough. ${ }^{3}$ Unfortunately the significance of using this approach (typical and atypical presentation) is limited because the clinical features of many infections overlap. ${ }^{4}$ Several studies before now from this region ${ }^{5,6,7}$ have identified Streptococcus pneumoniae and Mycoplasma as the commonest isolates from lower respiratory tract infections. A similar study on the upper respiratory tract infections (RTI) from the region ${ }^{8}$ showed a prevalence of Staphylococcus aureus and coliforms, with smaller proportiuons of Proteus mirabilis and Pseudomonas pyocynae. However to ensure appropriate therapy in RTI, current knowledge of the organisms that cause RTI and their antibiotic susceptibility is mandatory. ${ }^{8-11}$ The essence of this study, therefore, is to analyze the various isolated 
organisms obtained from sputum with a view to identifying the organism, to test their susceptibility and sensitivity to available antibiotics in use in the hospital and environ. The results of the finding would act as a guide in the empirical management of lower respiratory tract infections in the region.

\section{Materials and methods}

Patients seen over a one year period (Jamuary 1, 2005 to December 31, 2005) and who were diagnosed as having lower respiratory tract infections based on the clinical features were used for the study after an informed consent. The patients were recruited from the clinics and medical wards of the University of Benin Teaching Hospital, Benin City, Nigeria after an approval by the Ethical committee of the institution.

Information was collected using structured closed and open ended questionnaires which were researcher-administered to collect necessary information. Investigations done included sputum examinations for microscopy, culture and sensitivity. Patients were not commenced on antibiotic therapy prior to sputum collections and those currently on antibiotics were excluded from the study. Samples were cultured in blood agar (Oxoid No CM 271), McConkay agar (Oxoid No CM7) and chocolate agar. Nutrient agar (Oxoid No CMB) was used for sensitivity testing. Culture was by the streak plate method described after Robert Koch (1876). All the isolates were identified according to the methods advocated by Cowan and Steel. ${ }^{12}$ Colonial characteristics on media including size, ability to swarm, haemolysis on blood agar and gram staining were the specific methods involved. Such tests as oxidase, catalase and coagulase tests (for Staphylococcus aureus), carbohydrate utilization tests (for fermenters and non fermenters) , urease and citrate tests were also done.

The disc diffusion method which is a modification of Bauer and kirby ${ }^{13}$ was used for the susceptibility testing. Commercially prepared antibiotic discs were placed at least $2.5 \mathrm{~mm}$ apart on nutrient agar plates that had been inoculated with the test organisms using sterile forceps.

The different antimicrobial agents used and their disc contents were: augmentin 5ug, tetracycline 10ug, erythromycin 5ug, chloramphenicol 10ug, penicillin 1.5iu, ceftriazone 30ug, ofloxacin 5ug, perflacine 10ug, ceftazidime $5 \mathrm{ug}$ and ceftriaxone 5ug. Plates were incubated at 37oC for 24 hours after which the zone of inhibitions was measured. Organisms are sensitive to a particular drug if the zone of inhibition is $2.5 \mathrm{~cm}$ or more. The molecular weight of an antibiotics is also taken into consideration in determining sensitivity. While reporting results, S represents sensitivity of the organism to the antibiotic and $R$ represents resistance to the antibiotic. The sensitivity discs are from Abtek biological Ltd.

\section{Results}

Of 248 patients studied, one hundred and seventeen ( $47.18 \%$ ) were males and one hundred and thirty one (52.82\%) were females. Their ages ranged from 16 to 66 years with a median age of 41 years. Fifty nine $(47.2 \%)$ of the specimens yielded growth of bacteria while one hundred and eighty nine (52.8\%) yielded no growth.

of the fifty nine specimens that had positive cultures, 31 (52.5\%) grew Klebsiella pneumoniae, 3 (5.1\%) grew Escherichia coli, 4 (6.8\%) grew Proteus mirabilis, 6 (10.2\%) grew Staphylococcus aureus, 3 (5.1\%) grew Pseudomonas pyocynae, 2 (3.4\%) grew Proteus vulgaris, 1 ( $1.7 \%$ ) grew proteus morgani, 1 (1.7\%) grew Streptococcus pyogenes and 8 (13.6\%) yielded yeast cells. (Table 2).

When Klebsiella pneumoniae was isolated, the sensitivity pattern was better with chloramphenicol ${ }^{\odot}$ and gentamycin (CN) and ciprofloxacin where results were over $80 \%$. Isolates were however resistant to tetracycline,

( C CMS UNIBEN JMBR 2006; $5(2): 22-27$ 
24 Journal of Medicine and Biomedical Research

and cloxacillin (table 3). For Eschericlia coli (E. coli), isolates were sensitive to ceftazidime (CAZ), amoxicillin/clavulanate (augmentin) and Ciprofloxacin (CIP) and completely resistant to amoxicillin (AMX) (table 3). For Proteus mirabilis, isolates were sensitive to ceftriaxone (CRO), Amoxycillin/clavulanate (augmentin) and Ceftazidime (CAZ) (table 3) . The clinical presentation of studied groups consisted of history of cough with sputum production, fever, chest pain and dyspnoea; these were noticed in $86 \%$ - 100 of cases. An isolate of yeast was also observed (13.6\%) (table 3) .

\section{Discussion}

The importance of accurate diagnosis of the lower respiratory tract infections (RTI) has been identified as a key step towards limiting unnecessary antibacterial prescribing and improving the quality of necessary antibacterial prescribing.

This study shows the prevalence of Klebsiella pneumonae as the commonest isolate which is dissimilar to other studies from Nigeria. 5,6,7 A previous study of upper RTIs from this region ${ }^{8}$ showed the prevalent isolates to be Staphylococcus aureus and coliforms. The clinical presentation in these patients included history of cough with sputum production, fever, chest pain and dyspnoea. This mode of presentation in the studied patients are similar to those of an earlier study. ${ }^{6}$ In Nigeria, where tuberculosis ie endemic, the differential diagnosis is pulmonary tuberculosis. Another differential is acute exacerbation of chronic bronchitis (AECB) particularly in the middle aged to elderly. Chronic bronchitis is usually diagnosed in patients who have coughed up sputum on most days during at least 3 consecutive months for more than 2 consecutive years. Acute exacerbation of this chronic condition can be recognized by increased cough and dyspnoea along with an increase in quantity of sputum. ${ }^{14}$

This study has enabled us to have knowledge of local resistance pattern in Benin City and environ. The varying pattern of microbial isolates among different studies stresses the need to evaluate and monitor periodically changing susceptibility pattem of microflora especially in a hospital setting. ${ }^{15}$ Dosumu ${ }^{6}$ observed that streptococcus

Table 1: Sex Grouping of Patients

\begin{tabular}{lcc}
\hline Sex & Number & Percentage \\
\hline Male & 117 & 47.18 \\
Female & 131 & 52.82 \\
\hline Total & $\mathbf{2 4 8}$ & $\mathbf{1 0 0 . 0 0}$ \\
\hline
\end{tabular}

Table 2: Culture results and bacterial isolates from 248 patients with positive isolates

\begin{tabular}{lcc}
\hline Isolate & No/Frequency & Percentage \\
\hline Streptococcus pneumonia & 31 & 52.5 \\
Staphylococcus aureus & 6 & 10.2 \\
Proteus mirabilis & 4 & 6.8 \\
Pseudomonas pyocgnae & 3 & 5.1 \\
Eschericlia coli & 3 & 5.1 \\
Proteus vilgaris & 2 & 3.4 \\
Proteus morgani & 1 & 1.7 \\
Streptococcus pyogenes & 1 & 1.7 \\
Yeasts & 8 & 13.6 \\
\hline Total & 59 & 100 \\
\hline
\end{tabular}


Table 3: Antibiotic Susceptibility Pattern of isolates to representative antibiotics showing number and percentage

\begin{tabular}{|c|c|c|c|c|c|c|c|c|c|c|c|c|}
\hline Isolate & No & 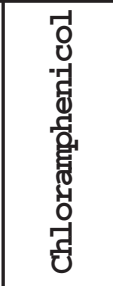 & 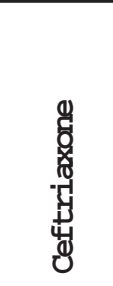 & 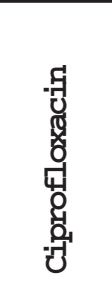 & 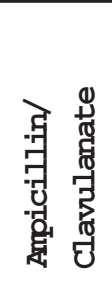 & 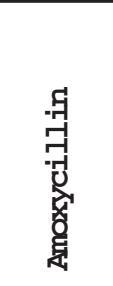 & 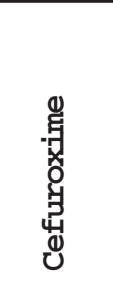 & 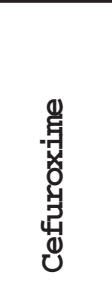 & 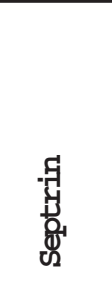 & 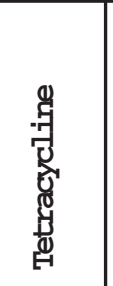 & 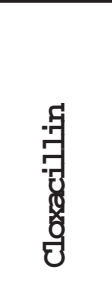 & 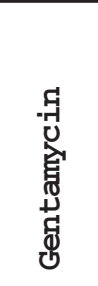 \\
\hline $\begin{array}{l}\text { Klebsiella } \\
\text { pneumoniae }\end{array}$ & 31 & $\begin{array}{c}28 \\
(90.22) \\
\end{array}$ & $\begin{array}{c}23 \\
(74.19) \\
\end{array}$ & $\begin{array}{c}25 \\
(64.64) \\
\end{array}$ & $\begin{array}{c}20 \\
(64.52) \\
\end{array}$ & $\begin{array}{c}1 \\
(3.22) \\
\end{array}$ & $\begin{array}{c}21 \\
(67.74) \\
\end{array}$ & $\begin{array}{c}20 \\
(64.52) \\
\end{array}$ & $\begin{array}{c}1 \\
(3.22) \\
\end{array}$ & - & - & $\begin{array}{c}29 \\
(93.54)\end{array}$ \\
\hline E. coli & 3 & \begin{tabular}{|c|}
1 \\
$(33.33)$ \\
\end{tabular} & $3(100)$ & $3(100)$ & $3(100)$ & - & $\begin{array}{c}2 \\
60.67) \\
\end{array}$ & $\begin{array}{c}1 \\
(3.33) \\
\end{array}$ & - & - & - & $\begin{array}{c}2 \\
(66.67)\end{array}$ \\
\hline $\begin{array}{l}\text { Proteus } \\
\text { Mirabilis }\end{array}$ & 4 & - & $3(75)$ & $3(75)$ & $3(75)$ & - & $2(50)$ & $4(100)$ & - & - & - & $3(75)$ \\
\hline $\begin{array}{l}\text { Proteus } \\
\text { vulgaris }\end{array}$ & 2 & - & $2(100)$ & $2(100)$ & 1 (50) & - & 1 (50) & $2(100)$ & - & - & - & $(100)$ \\
\hline $\begin{array}{l}\text { Proteus } \\
\text { Morgani } \\
\end{array}$ & 1 & $1(100)$ & $1(100)$ & $1(100)$ & $1(100)$ & - & - & $1(100)$ & - & - & - & $1(100)$ \\
\hline $\begin{array}{l}\text { Streptoe } \\
\text { Pyogenes }\end{array}$ & 1 & 1 (100) & $1(100)$ & $1(100)$ & - & - & $1(100)$ & $1(100)$ & - & - & $\begin{array}{ll}- \\
-\end{array}$ & $\begin{array}{ll}- \\
-\end{array}$ \\
\hline $\begin{array}{l}\text { Staph. } \\
\text { Aureus }\end{array}$ & $\begin{array}{c}6 \\
(83.33) \\
\end{array}$ & \begin{tabular}{|c}
5 \\
$(66.67)$ \\
\end{tabular} & $\begin{array}{c}4 \\
(66.67) \\
\end{array}$ & $\begin{array}{c}4 \\
(83.33) \\
\end{array}$ & $\begin{array}{c}5 \\
(16.67) \\
\end{array}$ & $\begin{array}{c}1 \\
(66.67)\end{array}$ & $\begin{array}{c}4 \\
(83.33) \\
\end{array}$ & $\begin{array}{c}5 \\
(33.33) \\
\end{array}$ & $\begin{array}{c}2 \\
(16.76)\end{array}$ & $\begin{array}{c}1 \\
(16.67)\end{array}$ & $\begin{array}{c}1 \\
(66.67)\end{array}$ & 4 \\
\hline $\begin{array}{l}\text { Pseudomo } \\
\text { Pyocynae }\end{array}$ & 3 & - & $\begin{array}{c}2 \\
(66.67) \\
\end{array}$ & $\begin{array}{c}2 \\
(66.67) \\
\end{array}$ & - & - & - & $3(100)$ & - & - & - & $3(100)$ \\
\hline Yeast Cells & 8 & & & & & & & & & & & \\
\hline
\end{tabular}

pneumoniae was the predominant isolate and cause of lobar pneumonia. Macfarlane et $a 1^{5}$ also made similar observation. However, in this study, there was no single isolate of Streptococcus. pneumoniae. Rather, Klebsiella pneumoniae was the predominant isolate, accounting for over $50 \%$ of the total isolates. It is difficult to offer a reasonable explanation for the inability to isolate Streptococcus pneumoniae in this study. It could be a result of underdiagnosis or that the methodology was not good enough to isolate the organism. Another useful explanation is that most patients who may be infected with Streptococcus pneumoniae may have had some unsuccessful antibiotic treatment which will make the organism difficult to grow in the normal growth medium.

Elsewhere, Haemopholus influenzae has been incriminated in upper respiratory tract infection. ${ }^{16,17}$ In this prospective study, there ( CMS UNIBEN JMBR 2006; $5(2): 22-27$ was no isolate of Haemophilus influenzae. The reason for its absence may be explained by the fact that people resort to self medication and use antibiotics indiscriminately and improperly. This habit of antibiotic abuse sensitizes organisms and not really kill them. Although not killed, they will however not be able to grow in the normal growth medium. This may explain the reason for the inability to isolate Haemophilus influenzae and Streptococcus pneumoniae routinely because of their fastidious nature. Klebsiella pneumoniae which accounted for over $50 \%$ of the total isolates was more than $80 \%$ susceptible to chloramphenicol, ciprofloxacin, ceftazidime, ceftriazone, Zinacerf = cefuroxime and amoxicillin/clavrlanate. It was $100 \%$ resistant to amoxicill in, cotrimoxazole, tetracycline and cloxacillin.

Yeast cells accounted for $14 \%$ of the total isolates. These yeast cells may be the altemate 
forms of dimorphic moulds. This however cannot be ascertained since the culture was incubated at $37^{\circ} \mathrm{C}$. It is pertinent however to note that yeast cells were isolated.

Staphylococcus aureus accounted for 8\% of total isolates and was over 83\% susceptible to chloramphenicol, amoxycillin/clavulanate, ceftriazone and 60\% susceptible to ceftazidime, ciprofloxacin, Zinacerf and gentamycin. It was however, 100\% resistant to Cotrimoxazole, tetracycline, cloxacillin and amoxicillin.

Proteus mirabilis accounted for 7\% of total isolates and was 75\% susceptible to ceftazidime, ciprofloxacin, amoxycillin/ clavrlanate, ceftriazone and gentamycin. It was 100\% resistant to chloramphenicol, amoxycillin, cotrimoxazole, tetracycline and cloxacillin. The presence of other isolates like Pseudormonas aeruginosae, streptococcus pyogenes, Moxarella morgani, Escherichia coli can be regarded as insignificant among organisms isolated from the lower respiratory tract in this study.

Generally Amoxycillin/clavulanate, Ceftazidime, Ceftriazone, Ciprofloxacin and gentamycin would make an important contribution for the effective management of organisms incriminated in lower respiratory tract infection. Judging from the result of this study, the removal of amoxycillin, tetracycline, cotrimoxazole and cloxacillin from the list of essential drugs prescribed in the hospital should be encouraged.

\section{References}

1 Sofowora E.O. and Onadeko B. Complications and prognostic factors in pneumonia among Nigerians. Nig. Med. J. 1973; Vol. 3, 1447.

2 Memish ZA, Venkatesh S and Shibe A.M. Impact of travel on international spread of antimicrobial resstance. International Journal of Antimicrobial agents. 2003; 21:135142.

3. Barleff JG et al. Community Acquired pneumona in adults. Guidelines for management. Clin Infect. Dis 1998, 26:811.
4 Wallace R J(Jr), Musher DM, Martin RR. Haemophilus influenzae pneumona in adults. American Journal of Medicine 1978; 64:87-93.

5. Macfarlane JT, Adegboye DS, Warren MJ . Mycoplasmo pneumonia and the aetiology of lobar pneumonia in Northern Nigeria, Thorax 1999, 34 (6) : 713-19

6. Dosumu E.A. Lobar pneumonia in Nigerians. Nigerian Medical Practitioner 2002; $41(5 / 6): 65-8$.

7. Isah AO, Ohaju-Obodo J. An open evaluation of the efficacy and safety of the new macrolide roxithromycin in the treatment of lower respiratory tract infections and pneumonia in Nigerian patients. West Afr. J. Med. 1996; $15(2)$ : 111-6.

8. Ogisi FO, Mordi RM and Okolugbo NE. Bacteriology of chronic maxillary sinusitis; A four-year retrospective analysis. JMBR 2004; Vol 3 No 2: 73-74.

9. Garan J. Performance in practice. Bacteriological efficacy in patients with drug resistant. Streptococcus pneumonia. Clinical Microbiology and Infection; 2004; 10 (suppl 2) : 28-35.

10. Klugman K.P. Surveillance for the future. Global strategies to control resistance. $11^{\text {th }}$ International Congress on infectious disease. Cancum, Mexico. 4-7 March 2004, Abstract 30. 007.

11. Lonks JR, Garan J and Medetros AA. Implications of antimicrobial resistance in the empirical treatment of community acquired respiratory tract infections. The case of macrolides. Journal of Antimicrobial Chemotherapy 2002; 50: 87-92.

12. Cowan ST and Steel KJ. Manual for Identification of Medical Bacteria. $2^{\text {nd }}$ editions. London: Cambridge University Press, 1974, 205-9.

13. Bauer WA, Kirby MM, Sherris JC and Truck M. Antibiotic susceptibility testing by standardized single disc method Amer. J. Clin. Path 1966; 45:4.

14. Aboussouan LS. Acute exacerbations of chronic bronchitis; focusing management for optimum results. Post grad Med 1996; 99 (4) : 89-98

( CMS UNIBEN JMBR 2006; $5(2): 22-27$ 
15. Obunje OK, Ekere AU. Changing patterns of microflora in antibiotic treated traumatic wounds. A private hospital based study . Nig. Jour Orth and Trauma. 2002; 1 (1) : 2528.

16. Sethi S, Wrong C, Grant BJ. Strain specific immune response to Haemophilus influenzae in chronic obstructive Pulmonary disease.
Amkerican Journal of Respiratory and Critical Care Medicine 2004; 169: 442-53.

17. Niederman MS. Does the presence of antibodies justify the use of antibiotics in exacerbations of chronic bronchitis. American Journal of Respiratory and Critical Care Medicine 2004; 169: 434-35. 